\title{
Gestational age at birth and child special educational needs: a UK representative birth cohort study
}

\section{Corresponding author:}

Neora Alterman

National Perinatal Epidemiology Unit (NPEU), Nuffield Department of Population Health, University of Oxford, Old Road Campus, Headington, Oxford, UK

neora.alterman@gmail.com

\section{Authors and affiliations:}

Neora Alterman ${ }^{1}$, Samantha Johnson ${ }^{2}$, Claire Carson ${ }^{1}$, Stavros Petrou ${ }^{3}$, Oliver Rivero-Arias ${ }^{1}$, Jennifer K Kurinzcuk ${ }^{1}$, Alison Macfarlane ${ }^{4}$, Elaine Boyle ${ }^{2}$, Maria A Quigley ${ }^{1}$

${ }^{1}$ National Perinatal Epidemiology Unit (NPEU), Nuffield Department of Population Health, University of Oxford, Oxford, UK

${ }^{2}$ Department of Health Sciences, University of Leicester, Leicester, UK

${ }^{3}$ Nuffield Department of Primary Care Health Sciences, University of Oxford, Oxford, UK

${ }^{4}$ Department of Health Sciences, City University, London, UK

Word count: 2,641 words 


\section{ABSTRACT}

\section{Objective:}

To examine the association between gestational age at birth across the entire gestational age spectrum and special education needs (SEN) in UK children at 11 years of age.

\section{Methods:}

The Millennium Cohort Study is a nationally representative longitudinal sample of children born in the UK during 2000-2002. Information about the child's birth, health and sociodemographic factors was collected when children were 9 months old. Information about presence and reasons for SEN was collected from parents at age 11. Adjusted relative risks (aRR) were estimated using modified Poisson regression, accounting for confounders.

\section{Results:}

The sample included 12,081 children with data at both time points. The overall prevalence of SEN was $11.2 \%$, and it was inversely associated with gestational age. Among children born $<32$ weeks of gestation, the prevalence of SEN was $27.4 \%$, three times higher than among those born at 40 weeks (aRR=2.89; 95\% Cl 2.02, 4.13). Children born early term (37-38 weeks) were also at increased risk for SEN (aRR=1.33; 95\% Cl 1.11, 1.59); this was the same when the analysis was restricted to births after labour with spontaneous onset. Birth before full term was more strongly associated with having a formal statement of SEN or SEN for multiple reasons.

\section{Conclusion:}

Children born at earlier gestational ages are more likely to experience SEN, have more complex SEN and require support in multiple facets of learning. This association was observed even among children born early-term and when labour began spontaneously.

\section{What is already known on this topic?}

- Preterm birth, especially extremely preterm birth, is a risk factor for neurodevelopmental sequelae and poor attainment in school.

- Special educational needs are more prevalent in children born at earlier gestational ages, even in children born at 37-38 weeks compared with 40 weeks.

What this study adds?

- Children born at 37-38 weeks of gestation are at moderately elevated risk of special educational needs even if labour began spontaneously.

- The risk of special educational needs following birth at earlier gestational ages is not only greater, but children's needs tend to be more complex.

- Preterm birth is associated most strongly with special educational needs due to attentiondeficit/hyperactivity disorder (ADHD) or health/physical difficulties. 


\section{INTRODUCTION}

Children born preterm ( $<37$ weeks' gestation) are at elevated risk of long-term health problems [1], neurodevelopmental disorders [2] and poorer school performance [3,4]. The risk is highest in children born very preterm ( $<32$ weeks). These adversities culminate in a higher prevalence of special educational needs (SEN) among children born preterm [5] which may arise from a range of cognitive, learning, physical or behavioural difficulties. Children born extremely preterm ( $<28$ weeks) are more likely to have complex SEN because of impairments in multiple developmental domains $[6,7]$.

Most prior studies have focused solely on children born extremely preterm or have aggregated all preterm births $[8,9]$. Some studies have, however, identified a gradient of higher risk for any gestation shorter than 40 weeks $[10,11]$. The onset of birth is often not spontaneous, but planned through labour induction or pre-labour caesarean section. By 2018-19, planned births accounted for half of all births in England [12]. It is uncertain whether a relatively shorter pregnancy within term gestations is a risk factor for SEN when labour begins spontaneously.

We aimed to investigate the association between gestational age at birth and SEN at age 11 (final year of primary school) across the full spectrum of gestation and specifically within births at term that began spontaneously. We further aimed to investigate the reasons for SEN in children born preterm compared to those born at term.

\section{METHODS}

\section{Millennium Cohort Study}

The Millennium Cohort Study (MCS) is a nationally representative longitudinal study of 18,818 children born in the UK between September 2000 and January 2002. The sample was drawn from the universal Child Benefit register at the age of 9-10 months. The sample does not include babies who died prior to the age at sampling, but these constituted 5.5 in 1000 births [13]. A clusterstratified sampling design was employed where electoral wards were sampled as clusters and wards 
with a high proportion of disadvantaged families or ethnic minorities were over-sampled to allow for adequate representation [14]. The smaller UK countries were also over-sampled. Initial interviews with the main carer, usually the mother, were conducted when the child was aged 9-10 months and subsequently every 2-4 years, collecting a wide range of information about demographics, health and development. The current study uses data collected at the 9-month survey and the age-11 survey. The latter was conducted when $95.5 \%$ of children were in their final year of primary school.

\section{Gestational age at birth}

Gestational age in weeks was ascertained from the mother's report of estimated date of delivery and actual date of birth. This information has been shown to have high agreement with linked routine hospital records, except for births post term ( $\geq 42$ weeks) [15]. Completed gestational weeks were categorised as 23-32 weeks (very preterm), 32-33 weeks (moderately preterm), 34-36 weeks (late preterm), 37-38 weeks (early term), 39 weeks, 40 weeks (both defined full term) and 41 weeks (late term) (Table 1) [16]. 
Table 1: Characteristics of MCS children included in this study by gestational age

\begin{tabular}{|c|c|c|c|c|c|c|c|c|c|}
\hline & $\begin{array}{c}\text { Very } \\
\text { preterm } \\
<32^{*} \\
\mathrm{n}\left(\%^{* *}\right)\end{array}$ & $\begin{array}{c}\text { Moderately } \\
\text { preterm } \\
32-33 \\
\mathrm{n}(\%)\end{array}$ & $\begin{array}{c}\text { Late } \\
\text { preterm } \\
34-36 \\
\mathrm{n}(\%)\end{array}$ & $\begin{array}{c}\text { Early term } \\
\text { 37-38 } \\
\text { n (\%) }\end{array}$ & $\begin{array}{c}\text { Full term } \\
\begin{array}{c}39 \\
n(\%)\end{array}\end{array}$ & $\begin{array}{l}\text { Full term } \\
\begin{array}{l}40 \\
n(\%)\end{array}\end{array}$ & $\begin{array}{l}\text { Late term } \\
\qquad \begin{array}{c}41 \\
n(\%)\end{array}\end{array}$ & $\begin{array}{l}\text { Total } \\
\text { n (\%) }\end{array}$ & P-value*** \\
\hline & $143(1.2)$ & $135(1.1)$ & $732(6.6)$ & $2,460(20.6)$ & $2,613(21.3)$ & $3,438(28.6)$ & $2,560(20.6)$ & $12,081(100.0)$ & \\
\hline \multicolumn{10}{|c|}{ Sociodemographic characteristics } \\
\hline Mean** maternal age (SD) & $27.6(5.9)$ & $30.0(6.2)$ & $28.3(6.2)$ & $28.4(5.9)$ & $28.4(6.0)$ & $27.8(6.0)$ & $28.1(5.9)$ & $28.2(6.0)$ & 0.020 \\
\hline White child ethnicity & $114(81.2)$ & $115(90.7)$ & $616(86.1)$ & $2,017(83.2)$ & $2,163(84.5)$ & $2,866(84.6)$ & $2.266(89.3)$ & $10,157(85.4)$ & $<0.001$ \\
\hline Partnership status & & & & & & & & & 0.132 \\
\hline Married & $91(55.5)$ & $90(67.4)$ & $420(50.7)$ & $1,575(58.4)$ & $1,627(56.9)$ & $2,125(56.0)$ & $1,562(56.0)$ & $7,490(56.5)$ & \\
\hline Cohabiting & 31 (28.9) & $30(22.6)$ & $183(28.2)$ & $528(24.9)$ & $623(26.2)$ & $801(26.6)$ & $651(28.6)$ & $2,847(26.7)$ & \\
\hline Single mother & $21(15.6)$ & $15(10.0)$ & $129(21.0)$ & $357(16.8)$ & $363(16.9)$ & $512(17.4)$ & $347(15.5)$ & $1,744(16.9)$ & \\
\hline \multicolumn{4}{|l|}{ Maternal education } & & & & & & 0.006 \\
\hline Higher (University) & $43(26.8)$ & $44(32.4)$ & $224(25.4)$ & 749 (26.0) & 861 (28.9) & $1,111(28.2)$ & $908(31.8)$ & $3,940(28.5)$ & \\
\hline Medium (A-level) & $16(11.3)$ & $14(11.6)$ & $83(11.3)$ & $373(14.3)$ & $359(13.0)$ & $516(14.3)$ & $401(15.0)$ & 1,762 (13.9) & \\
\hline Lower (GCSE) & $50(37.5)$ & $62(46.5)$ & $308(43.2)$ & 903 (40.6) & $947(39.3)$ & 1,232 (39.2) & $930(39.1)$ & 4,432 (39.8) & \\
\hline None or other & $34(24.5)$ & $15(9.5)$ & $117(20.2)$ & 435 (19.1) & 446 (18.9) & $579(18.3)$ & $321(14.1)$ & 1,947 (17.8) & \\
\hline \multicolumn{2}{|c|}{ Household socioeconomic class } & & & & & & & & $0.013^{* * * *}$ \\
\hline Managerial/professional & $49(30.7)$ & $53(44.0)$ & $308(38.4)$ & $1,034(39.2)$ & $1,130(39.9)$ & $1,454(39.8)$ & $1,204(44.4)$ & $5,232(40.5)$ & \\
\hline Intermediate & $35(24.3)$ & $32(25.3)$ & $129(17.1)$ & $474(19.3)$ & $505(19.4)$ & $680(19.8)$ & $497(19.2)$ & $2,352(19.4)$ & \\
\hline Routine/manual & $55(39.8)$ & $40(24.0)$ & $258(38.5)$ & $840(36.6)$ & $841(34.6)$ & $1,098(33.7)$ & $763(32.6)$ & $3,895(34.6)$ & \\
\hline Never/long-term & $4(5.2)$ & $10(6.8)$ & $37(6.0)$ & $112(5.0)$ & $137(6.1)$ & $206(6.7)$ & $96(3.8)$ & $602(5.6)$ & \\
\hline
\end{tabular}

* The median gestational age in the group of $<32$ weeks was 29.5 weeks, with $0.3 \%$ born $\leq 27$ weeks (extremely preterm)

** Percentages and means are weighted to account for study design, non-response and loss to follow-up at age 11

*** Chi-2 tests for categorical variables and $\mathrm{F}$ tests for continuous variables

$* * * *$ Based on small numbers

Table continues on next page 


\begin{tabular}{|c|c|c|c|c|c|c|c|c|c|}
\hline & $\begin{array}{c}\text { Very } \\
\text { preterm } \\
<32^{*} \\
\mathrm{n}(\% * *) \\
\end{array}$ & $\begin{array}{c}\text { Moderately } \\
\text { preterm } \\
32-33 \\
\mathrm{n}(\%) \\
\end{array}$ & $\begin{array}{c}\text { Late } \\
\text { preterm } \\
34-36 \\
\mathrm{n}(\%) \\
\end{array}$ & $\begin{array}{l}\text { Early term } \\
\qquad \begin{array}{c}\text { 37-38 } \\
\text { n (\%) }\end{array}\end{array}$ & $\begin{array}{c}\text { Full term } \\
\begin{array}{c}39 \\
\text { n (\%) }\end{array}\end{array}$ & $\begin{array}{c}\text { Full term } \\
\begin{array}{c}40 \\
n(\%)\end{array}\end{array}$ & $\begin{array}{c}\text { Late term } \\
\qquad \begin{array}{c}41 \\
\mathrm{n}(\%)\end{array}\end{array}$ & $\begin{array}{l}\text { Total } \\
\text { n (\%) }\end{array}$ & P-value*** \\
\hline \multicolumn{10}{|c|}{ Pregnancy and postnatal characteristics } \\
\hline Male & $68(50.2)$ & $75(63.7)$ & $381(52.5)$ & $1,271(52.2)$ & $1,286(51.0)$ & $1,706(49.6)$ & $1,276(51.5)$ & $6,063(51.2)$ & 0.184 \\
\hline Mean** birthweight in $\mathrm{Kg}$ (SD) & $1.27(0.38)$ & $2.00(0.44)$ & $2.62(0.50)$ & $3.14(0.49)$ & $3.35(0.45)$ & $3.48(0.45)$ & $3.65(0.45)$ & $3.32(0.60)$ & $<0.001$ \\
\hline Multiple birth & $38(26.1)$ & $30(24.5)$ & $108(14.6)$ & $123(5.5)$ & $26(1.1)$ & $6(0.2)$ & $0(0.0)$ & $331(3.0)$ & $<0.001$ \\
\hline Firstborn child & $76(52.7)$ & $64(49.1)$ & $328(42.3)$ & $905(38.3)$ & $995(37.4)$ & $1,465(42.3)$ & $1,197(47.3)$ & $5,030(41.7)$ & $<0.001$ \\
\hline Maternal smoking & & & & & & & & & 0.003 \\
\hline Never & $86(63.0)$ & $80(58.5)$ & 446 (57.9) & 1,671 (63.9) & $1,749(63.8)$ & 2,335 (64.1) & $1,772(65.7)$ & $8,139(63.8)$ & \\
\hline Gave-up in pregnancy & $19(10.4)$ & $21(15.0)$ & $99(13.8)$ & 264 (11.9) & $260(9.7)$ & 406 (12.9) & $315(13.6)$ & $1,384(12.2)$ & \\
\hline Smoked during pregnancy & $38(26.5)$ & $34(26.5)$ & $186(28.3)$ & $525(24.3)$ & $602(26.5)$ & $696(23.1)$ & $471(20.7)$ & $2,552(24.0)$ & \\
\hline Alcohol during pregnancy & $10(7.0)$ & $11(7.7)$ & $54(8.0)$ & $161(6.9)$ & $189(7.3)$ & $230(7.2)$ & $210(8.6)$ & $865(7.5)$ & 0.683 \\
\hline Labour induced & $16(8.6)$ & $28(16.6)$ & $196(26.2)$ & $717(28.7)$ & $566(21.4)$ & $798(22.0)$ & $1,215(46.4)$ & $3,536(28.3)$ & $<0.001$ \\
\hline Mode of birth & & & & & & & & & $<0.001$ \\
\hline Vaginal delivery & $58(41.3)$ & 57 (39.9) & $461(64.5)$ & $1,628(67.2)$ & $2,083(81.7)$ & 2,937 (87.1) & $2,146(85.2)$ & 9,370 (78.9) & \\
\hline Planned caesarean & $13(8.4)$ & $20(15.2)$ & $73(9.2)$ & $568(22.5)$ & $299(10.2)$ & $133(3.4)$ & $61(2.1)$ & $1,167(9.1)$ & \\
\hline Emergency caesarean & $71(50.4)$ & $58(44.9)$ & $198(26.3)$ & $262(10.3)$ & $226(8.1)$ & $362(9.5)$ & $351(12.7)$ & $1,528(12.0)$ & \\
\hline Neonatal intensive care & $125(91.7)$ & $133(85.0)$ & 296 (39.9) & $222(8.8)$ & $124(4.3)$ & $159(4.1)$ & $110(4.7)$ & $1,149(9.6)$ & $<0.001$ \\
\hline Month of birth & & & & & & & & & 0.170 \\
\hline September-December & $48(24.2)$ & $47(28.9)$ & $264(34.1)$ & $916(36.1)$ & $918(33.1)$ & $1,224(34.7)$ & $896(34.7)$ & $4,313(34.4)$ & \\
\hline January-April & $45(30.6)$ & $42(31.1)$ & $246(32.7)$ & $798(32.6)$ & $828(31.4)$ & $1,081(31.2)$ & 793 (29.9) & $3,833(31.4)$ & \\
\hline May-August & $50(45.2)$ & $46(40.0)$ & $222(33.1)$ & $746(31.3)$ & $867(35.5)$ & $1,133(34.0)$ & $871(35.4)$ & $3,935(34.2)$ & \\
\hline
\end{tabular}




\section{Special educational needs}

At the age 11 survey, parents were asked whether the school or local education authority had ever told them their child has SEN. Further information was collected on whether the child had a statement of SEN. This is a legal document that may be issued by the local authority following a statutory assessment and indicates the child has higher intensity of need (replaced in 2014 by an Education, Health and Care Plan). Those in process of assessment (48 children) were classified as without a statement. Additionally, information about the reason(s) for the child's SEN, i.e. the diagnosis or difficulty, was gathered using predefined and open-text responses. For the current study, we categorised the reported reasons for SEN into: learning difficulty, autism spectrum disorder (ASD), speech/language/communication difficulties, attention-deficit/hyperactivity disorder (ADHD), health/physical problem, and behavioural/emotional/social difficulties (Supplementary Table S-1). We further generated a variable designating whether the child had multiple SENs (more than a single category of reason for SEN). In several cases, the reason given for the child's SEN was being gifted or talented. If no additional evidence of SEN existed, these cases were classified as missing the outcome, as they might be due to misclassification.

\section{Exclusions and missing data}

Of the 18,818 children recruited to the MCS, 12,990 (69\%) participated in the age 11 survey (Figure 1). Children were excluded if the mother was not the main respondent at the initial survey or if gestational age was missing or implausible given the reported birthweight $[15,17]$. Post term births were excluded due to lower data quality [15]. Children with missing data on SEN or confounders were also excluded. The final study sample had a similar distribution of gestational age to the cohort of children originally recruited but was somewhat less socially advantaged (Table S-2).

\section{Statistical analyses}

Relative risks for the association between gestational age at birth and each of the outcomes were estimated using modified Poisson regression with gestational week 40 used as referent [18]. All 
potential confounders were collected at the 9-month survey. A priori adjustments were made for: mother's education level, multiple birth, child sex and month of birth (age within the school year) $[3,4]$. Additional potential confounders were mother's age, partnership status, smoking during pregnancy, alcohol consumption during pregnancy (none/light vs. moderate/heavy) [19], household's socio-economic class (based on last known occupation of the mother or her partner, if higher), ethnicity (white or non-white) and whether firstborn. Additional confounders associated with the exposure and SEN outcome at P-value $<0.1$ were assessed in separate socio-demographic and perinatal models. The effect of each variable removal was examined individually, both within a block (retaining if $p<0.10$ ) and when the variables from both blocks were combined, until only those independently associated with the outcome at P-value $<0.05$ were retained. Models of additional outcomes were adjusted for the same covariates to aid comparability. For analyses of reasons for SEN, we compared preterm births ( $<37$ weeks) with births at term (37-41 weeks). All analyses were conducted in Stata version 15. Analyses accounted for the clustered, stratified design using the survey commands, while also allowing for within-family clustering for multiples. Weights were applied to allow for non-response at the initial survey and loss to follow-up at age 11 [20]. Ethics approval for the MCS was granted from the Multicentre Research Ethics Committee. No further approvals were required for this study.

\section{Sensitivity analysis}

We restricted the analysis of multiple SENs to predefined reasons, not including those coded from open-text answers where reliability may be lower (Table S-1).

\section{Sub-group analyses}

We explored the associations of gestational age with SEN outcomes within the group of term-born children and where labour onset was spontaneous, i.e. excluding planned birth through induction of labour or planned caesarean section. 


\section{RESULTS}

\section{Descriptive characteristics}

The analysis sample included 12,081 children. Gestational age at birth was associated with birthweight and singleton birth in a 'dose-response' pattern. Additionally, it was associated with the following characteristics $(P<0.05)$ : maternal age, education, smoking, child ethnicity, being firstborn, and household socio-economic class (Table 1).

\section{The association between gestational age and SEN}

The proportion of children with any SEN was $11.2 \%$. This ranged from $9.5 \%$ in children born at 40 weeks to $27.4 \%$ in those born at $<32$ weeks (Table 2). There was an inverse association between gestational age and SEN, both before and after adjustment for confounders. The relative risk (RR) reached $2.89(95 \% \mathrm{Cl} 2.02,4.13)$ among children born very preterm compared to those born at 40 weeks. A statistically significant increase in risk ( $R R=1.33 ; 95 \% \mathrm{Cl} 1.11,1.59)$ was found even among children born at early term gestation. An exception to this trend were children born moderately preterm, who were not at higher risk than those born at 40 weeks. Children born at 41 weeks did not have a different risk compared with the reference group.

The proportion of children with a statement of SEN was $4.9 \%$. This ranged from $3.8 \%$ in children born at 40 weeks to $15.3 \%$ in children born very preterm (Table 2). The proportion of children with multiple SENs was $2.8 \%$, ranging from $2.0 \%$ for children born late term to $8.5 \%$ in very preterm. Of the children with multiple SENs, 38.3\% did not have a statement, and of the children that had a statement, $63.9 \%$ did not have multiple SENs. A 'dose-response' of increased risk with lower gestational age was observed for having a statement and multiple SENs, reaching aRR $=3.98(95 \% \mathrm{Cl}$ $2.24,7.06)$ and $a R R=3.32(95 \% \mathrm{Cl} 1.61,6.84)$ respectively for those born very preterm. The adjusted relative risk observed for statement and multiple SENs was generally higher than for any SEN (Figure 2). The result of a sensitivity analysis using only predefined reasons to measure multiple SENs was not materially different from the main result (Table S-3). 
We further examined these associations within a sub-group of births at term with spontaneous onset, excluding $38 \%$ of births where delivery was planned. The relative risk for SEN in births with spontaneous onset at early term was similar to that found for all births at early term ( $a R R=1.36 \mathrm{vs.}$ $a R R=1.33$ respectively), as was the relative risk of a statement of $S E N(a R R=1.31$ vs. $a R R=1.38)$ (Table 2). The relative risk for multiple SENs within spontaneous-onset births was slightly higher than that of all births at early term (aRR=1.75 vs. aRR=1.40).

Figure 1: MCS children included in study sample

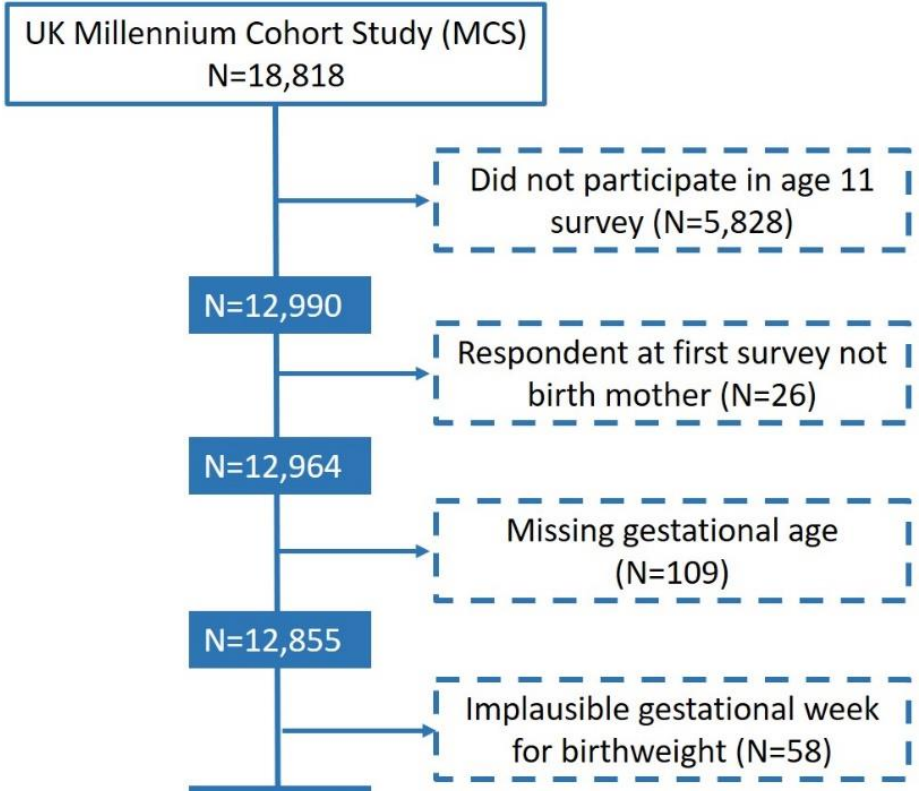

\section{$\mathrm{N}=12,318$}

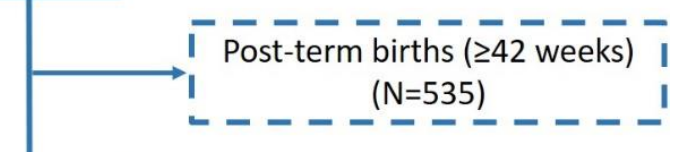

$\mathrm{N}=12,262$

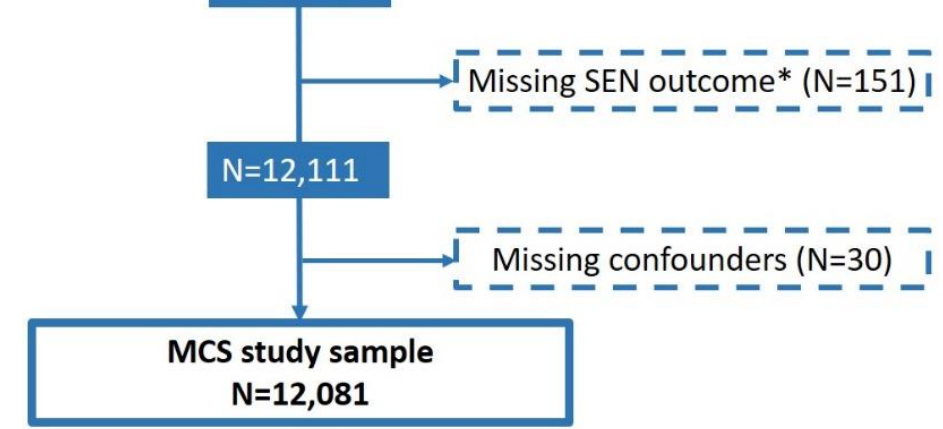

* 23 of which missing due to not attending school and 30 of which due to reason for SEN being a gifted or talented child (see methods). 
Table 2: The association between gestational age and any SEN, statement of SEN and multiple SENs at age 11 in the MCS children - all births and spontaneous-onset births at term only

\begin{tabular}{|c|c|c|c|c|c|c|c|c|}
\hline & Total & $\begin{array}{l}\text { Very preterm } \\
<32 \text { weeks } \\
\end{array}$ & $\begin{array}{l}\text { Moderately } \\
\text { preterm } \\
\text { 32-33 weeks }\end{array}$ & $\begin{array}{l}\text { Late preterm } \\
\text { 34-36 weeks }\end{array}$ & $\begin{array}{l}\text { Early term } \\
\text { 37-38 weeks }\end{array}$ & $\begin{array}{l}\text { Full term } \\
39 \text { weeks }\end{array}$ & $\begin{array}{l}\text { Full term } \\
40 \text { weeks }\end{array}$ & $\begin{array}{l}\text { Late term } \\
41 \text { weeks }\end{array}$ \\
\hline \multicolumn{9}{|l|}{ Any SEN } \\
\hline \multicolumn{9}{|l|}{ Total sample } \\
\hline $\begin{array}{l}\mathrm{N} \\
\mathrm{n}(\%)^{*}\end{array}$ & $\begin{array}{c}12,081 \\
1,243(11.2)\end{array}$ & $\begin{array}{c}143 \\
33(27.4)\end{array}$ & $\begin{array}{c}135 \\
15(10.6)\end{array}$ & $\begin{array}{c}732 \\
108(17.1)\end{array}$ & $\begin{array}{c}2,460 \\
283(12.7)\end{array}$ & $\begin{array}{c}2,613 \\
250(10.3)\end{array}$ & $\begin{array}{c}3,438 \\
315(9.5)\end{array}$ & $\begin{array}{c}2,560 \\
239(10.0)\end{array}$ \\
\hline $\operatorname{RR}(95 \% \mathrm{Cl})$ & & $2.88(2.02,4.11)$ & $1.11(0.62,2.01)$ & $1.80(1.40,2.31)$ & $1.34(1.11,1.61)$ & $1.08(0.90,1.30)$ & 1.00 & $1.05(0.88,1.26)$ \\
\hline Adjusted** RR (95\% Cl) & & $2.89(2.02,4.13)$ & $1.09(0.58,2.04)$ & $1.78(1.41,2.25)$ & $1.33(1.11,1.59)$ & $1.07(0.90,1.28)$ & 1.00 & $1.05(0.88,1.25)$ \\
\hline \multicolumn{9}{|c|}{ Spontaneous-onset term births } \\
\hline $\begin{array}{l}N \\
\mathrm{n}(\%)\end{array}$ & $\begin{array}{c}6,854 \\
651(9.9)\end{array}$ & - & - & - & $\begin{array}{c}1,246 \\
143(12.8)\end{array}$ & $\begin{array}{c}1,783 \\
162(9.4)\end{array}$ & $\begin{array}{c}2,526 \\
226(9.0)\end{array}$ & $\begin{array}{c}1,299 \\
120(9.6)\end{array}$ \\
\hline Adjusted RR (95\% Cl) & & - & - & - & $1.36(1.06,1.74)$ & $1.04(0.83,1.30)$ & 1.00 & $1.07(0.84,1.36)$ \\
\hline \multicolumn{9}{|l|}{ Statement of SEN } \\
\hline \multicolumn{9}{|l|}{ Total sample } \\
\hline $\begin{array}{l}\text { N } \\
\text { n (\%) }\end{array}$ & $\begin{array}{c}12,075 \\
561(4.9)\end{array}$ & $\begin{array}{c}143 \\
18(15.3)\end{array}$ & $\begin{array}{c}135 \\
8(6.7)\end{array}$ & $\begin{array}{c}732 \\
53(7.3)\end{array}$ & $\begin{array}{c}2,460 \\
127(5.4)\end{array}$ & $\begin{array}{c}2,609 \\
106(4.6)\end{array}$ & $\begin{array}{c}3,438 \\
134(3.8)\end{array}$ & $\begin{array}{c}2,558 \\
115(4.5)\end{array}$ \\
\hline $\operatorname{RR}(95 \% \mathrm{Cl})$ & & $4.02(2.29,7.07)$ & $1.76(0.77,4.04)$ & $1.91(1.33,2.75)$ & $1.41(1.03,1.94)$ & $1.21(0.90,1.63)$ & 1.00 & $1.18(0.88,1.58)$ \\
\hline Adjusted RR (95\% CI) & & $3.98(2.24,7.06)$ & $1.84(0.78,4.38)$ & $1.88(1.30,2.72)$ & $1.38(1.01,1.88)$ & $1.20(0.89,1.62)$ & 1.00 & $1.22(0.91,1.63)$ \\
\hline \multicolumn{9}{|c|}{ Spontaneous-onset term births } \\
\hline $\mathbf{N}$ & 6,850 & - & - & - & 1,246 & 1,780 & 2,526 & 1,298 \\
\hline n (\%) & $275(4.1)$ & & & & $64(5.2)$ & $56(3.6)$ & $96(3.6)$ & $59(4.5)$ \\
\hline Adjusted RR (95\% Cl) & & - & - & - & $1.31(0.88,1.96)$ & $1.00(0.68,1.48)$ & 1.00 & $1.29(0.88,1.89)$ \\
\hline \multicolumn{9}{|l|}{ Multiple SENs } \\
\hline \multicolumn{9}{|l|}{ Total sample } \\
\hline $\mathbf{N}$ & 12,053 & 141 & 135 & 730 & 2,455 & 2,611 & 3,429 & 2,552 \\
\hline
\end{tabular}




\begin{tabular}{|c|c|c|c|c|c|c|c|c|}
\hline n (\%) & $287(2.8)$ & $11(8.5)$ & $3(2.5)$ & $28(6.0)$ & $68(3.1)$ & 68 (2.9) & $70(2.1)$ & $39(2.0)$ \\
\hline RR (95\% Cl) & & $4.01(2.08,7.72)$ & $1.19(0.35,4.11)$ & $2.84(1.55,5.22)$ & $1.46(0.99,2.15)$ & $1.36(0.92,2.01)$ & 1.00 & $0.94(0.60,1.49)$ \\
\hline Adjusted RR (95\% Cl) & & $3.32(1.61,6.84)$ & $1.09(0.30,3.93)$ & $2.54(1.41,4.60)$ & $1.40(0.95,2.05)$ & $1.32(0.90,1.94)$ & 1.00 & $0.97(0.62,1.53)$ \\
\hline \multicolumn{9}{|c|}{ Spontaneous-onset term births } \\
\hline $\begin{array}{l}N \\
\text { n (\%) }\end{array}$ & $\begin{array}{c}6,841 \\
152(2.4)\end{array}$ & - & - & - & $\begin{array}{c}1,244 \\
39(3.7)\end{array}$ & $\begin{array}{c}1,782 \\
44(2.7)\end{array}$ & $\begin{array}{c}2,521 \\
49(1.9)\end{array}$ & $\begin{array}{c}1,294 \\
20(1.8)\end{array}$ \\
\hline Adjusted RR (95\% Cl) & & - & - & - & $1.75(1.03,2.95)$ & $1.41(0.86,2.29)$ & 1.00 & $1.00(0.57,1.73)$ \\
\hline
\end{tabular}

* Percentages are weighted to account for sampling design, non-response to the MCS, and loss to follow-up

** Adjusted for white ethnicity, maternal education, household socioeconomic class, child sex, month of birth, multiple birth 
Figure 2: Any SEN, statement of SEN and multiple SENs in the MCS children at age 11 by gestational age

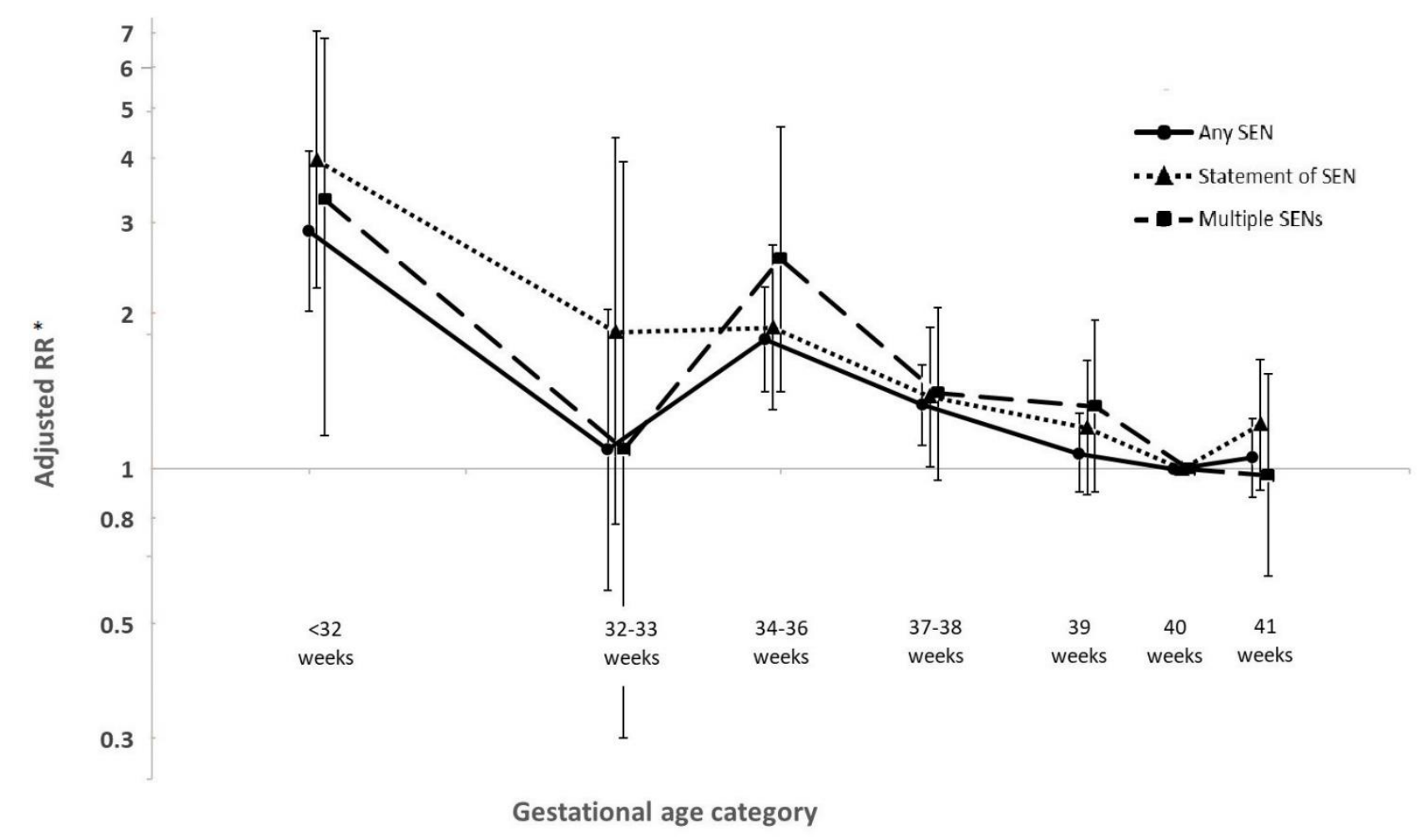

* Adjusted for ethnicity, maternal education, household socioeconomic class, child sex, month of birth, multiple birth 
Reasons for SEN in children born preterm and at term

Learning difficulty was the most frequent reason for SEN, reported for $6.8 \%$ of the sample and comprising $61.9 \%$ of those with SEN. ASD was reported as the reason for SEN in $19.5 \%$ of children with SEN, followed by speech/language/communication difficulties (15.2\%), ADHD (14.3\%), health/physical problem (13.1\%) and behavioural/emotional/social difficulties (11.1\%). Table 3 presents the adjusted relative risk for each reason for SEN in children born preterm compared with term. Preterm-born children were at increased risk for all SEN reasons examined, although the adjusted relative risks for SEN because of speech/language/communication and behavioural/emotional/social problems were not statistically significant. There was evidence of a stronger effect of preterm birth on SEN in relation to ADHD (aRR=2.22;95\% $\mathrm{Cl} 1.11,4.47)$ and health/physical needs ( $\mathrm{aRR}=2.86 ; 95 \% \mathrm{Cl} 1.80,4.54)$ compared with the effect on any SEN overall. 
Table 3: Reasons for SEN at age 11 in the MCS children born preterm compared with term gestation

\begin{tabular}{|c|c|c|c|c|c|c|c|c|c|c|c|c|c|c|c|}
\hline & \multirow[t]{2}{*}{$\mathbf{N}^{*}$} & \multicolumn{2}{|c|}{ Any SEN } & \multicolumn{2}{|c|}{$\begin{array}{l}\text { Learning } \\
\text { difficulty }\end{array}$} & \multicolumn{2}{|c|}{$\begin{array}{l}\text { Autism Spectrum } \\
\text { Disorder (ASD) }\end{array}$} & \multicolumn{2}{|c|}{$\begin{array}{l}\text { Speech/ } \\
\text { communication } \\
\text { difficulties }\end{array}$} & \multicolumn{2}{|c|}{$\begin{array}{l}\text { Attention Deficit } \\
\text { Hyperactivity } \\
\text { Disorder } \\
\text { (ADHD) }\end{array}$} & \multicolumn{2}{|c|}{ Health/physical } & \multicolumn{2}{|c|}{$\begin{array}{l}\text { Behavioural } \\
\text { /emotional } \\
\text { /social difficulties }\end{array}$} \\
\hline & & $\begin{array}{l}\mathrm{n} \\
(\%)^{* *}\end{array}$ & $\begin{array}{l}\text { Adjusted } \\
\mathrm{RR}^{* * *} \\
(95 \% \mathrm{Cl})\end{array}$ & $\begin{array}{l}\mathrm{n} \\
(\%)\end{array}$ & $\begin{array}{l}\text { Adjusted RR } \\
(95 \% \mathrm{Cl})\end{array}$ & n (\%) & $\begin{array}{l}\text { Adjusted RR } \\
(95 \% \mathrm{Cl})\end{array}$ & $\begin{array}{l}\mathrm{n} \\
(\%)\end{array}$ & $\begin{array}{l}\text { Adjusted RR } \\
(95 \% \mathrm{Cl})\end{array}$ & n (\%) & $\begin{array}{l}\text { Adjusted RR } \\
(95 \% \mathrm{Cl})\end{array}$ & n (\%) & $\begin{array}{l}\text { Adjusted } \\
\text { RR } \\
(95 \% \mathrm{Cl})\end{array}$ & n (\%) & $\begin{array}{l}\text { Adjusted } \\
\text { RR } \\
(95 \% \mathrm{Cl})\end{array}$ \\
\hline Total & 12,053 & $\begin{array}{l}1,215 \\
(11.0)\end{array}$ & & $\begin{array}{l}772 \\
(6.8)\end{array}$ & & $\begin{array}{l}235 \\
(2.1)\end{array}$ & & $\begin{array}{l}175 \\
(1.7)\end{array}$ & & $\begin{array}{l}149 \\
(1.6)\end{array}$ & & $\begin{array}{l}162 \\
(1.4)\end{array}$ & & $\begin{array}{l}114 \\
(1.2)\end{array}$ & \\
\hline $\begin{array}{l}37-41 \\
\text { weeks }\end{array}$ & 11,047 & $\begin{array}{l}1,063 \\
(10.3)\end{array}$ & 1.00 & $\begin{array}{l}678 \\
(6.5)\end{array}$ & 1.00 & $\begin{array}{l}209 \\
(2.0)\end{array}$ & 1.00 & $\begin{array}{l}155 \\
(1.6)\end{array}$ & 1.00 & $\begin{array}{l}128 \\
(1.4)\end{array}$ & 1.00 & $\begin{array}{l}129 \\
(1.2)\end{array}$ & 1.00 & $\begin{array}{l}99 \\
(1.1)\end{array}$ & 1.00 \\
\hline $\begin{array}{l}<37 \\
\text { weeks }\end{array}$ & 1,006 & $\begin{array}{l}152 \\
(17.4)\end{array}$ & $\begin{array}{l}1.66 \\
(1.38,2.01)\end{array}$ & $\begin{array}{l}94 \\
(9.6)\end{array}$ & $\begin{array}{l}1.40 \\
(1.08,1.83)\end{array}$ & $\begin{array}{l}26 \\
(3.4)\end{array}$ & $\begin{array}{l}1.68 \\
(1.02,2.77)\end{array}$ & $\begin{array}{l}20 \\
(2.3)\end{array}$ & $\begin{array}{l}1.46 \\
(0.83,2.55)\end{array}$ & $\begin{array}{l}21 \\
(3.5)\end{array}$ & $\begin{array}{l}2.22 \\
(1.11 .4 .47)\end{array}$ & $\begin{array}{l}33 \\
(3.5)\end{array}$ & $\begin{array}{l}2.86 \\
(1.80 \\
4.54)\end{array}$ & $\begin{array}{l}15 \\
(2.8)\end{array}$ & $\begin{array}{l}2.16 \\
(0.88 \\
5.29)\end{array}$ \\
\hline
\end{tabular}

* 28 observations missing reason for SEN not included

$* *$ Weighted percentages from all children per gestational age group

*** Adjusted for white ethnicity, maternal education, household socioeconomic class, child sex, month of birth, multiple birth 


\section{DISCUSSION}

We have shown that the risk of SEN among 11-year-old children in the UK increases with lower gestational age at birth. We have further shown that children born preterm are more likely to have complex SEN or for multiple reasons than children born at term. Children born very preterm had an almost three-fold higher risk of any SEN and four-fold higher risk for a statement of SEN or multiple reasons for SEN compared with children born at 40 weeks of gestation. Our findings are comparable to a Scottish study where children born at $28-32$ weeks were 2.7 times more likely to have SEN at any point during their school career [11]. A prior national UK study found relative risks of SEN substantially higher than those described here, but included only extremely preterm children born $<26$ weeks of gestation [8]. Furthermore, our results regarding multiple SENs are in line with prior studies examining children born very and extremely preterm that found a three-fold increased risk of having impairments in multiple domains affecting learning $[6,21]$.

Our study explored the full gestation spectrum and we observed a gradient of risk not only for children born preterm, but for birth at any gestational week lower than 40 . Effects were statistically significant starting at early term (37-38 weeks) where $12.7 \%$ of the children had SEN compared with $9.5 \%$ of the children in week 40 . This modest additional risk may potentially have a large population effect since almost 1 in 4 births occur at these gestational weeks because of a high rate of planned early births $[12,22]$. A prior study found that a planned early birth was associated with an elevated risk for being developmentally vulnerable at age 5 , which was higher than the excess risk associated with the lower gestational age [23]. However, another study did not identify an interaction between SEN and type of birth onset [11], and our study did not find a weaker effect of birth at early term when including only those with spontaneous labour onset. This might imply that gestation is the main driver leading to SEN in children born at early term gestations, rather than a fetal or maternal reason leading to iatrogenic early birth. 
The moderately preterm group diverged from the 'dose-response' pattern of increasing risk with decreasing gestational age, but the reasons for this are unclear. In the MCS, it has previously been shown that this group is socio-economically more advantaged and ethnically less diverse than the adjacent groups [4,24], however these factors were adjusted for in the models. This divergence in the dose response was not identified in other populations [11] and may therefore be due to unmeasured confounders or to chance, given the low numbers with reported SEN in this group.

Regarding parent-reported reasons for SEN, preterm birth was most strongly associated with health/physical needs including sensory impairments. Of the children born at term, $1.2 \%$ were reported to have SEN for this reason compared with 3.5\% of the children born preterm. A previous study using routine educational records similarly observed the strongest associations with SEN due to physical/motor disability and sensory impairments, along with intellectual disability [25]. Preterm birth was also associated more strongly with SEN for ADHD compared with SEN for any reason. This finding is consistent with previous research reporting higher risks of ADHD in preterm populations [26].

The main strength of our study is use of a nationally representative sample large enough to explore the association of SEN with the complete gestation spectrum while adjusting for detailed potential confounders. A further strength is the examination of complex SEN and exploration of reasons for SEN, allowing a better understanding of the special needs characteristic of preterm-born children.

The main study limitation was reliance on parents' reporting about SEN, which may be prone to bias. However, during the relevant time frame, the Department of Education register in England may not have been the gold standard for SEN either, since 1 in 4 children in England were recorded as having SEN at age 11 [27]. These are comprised of different levels including 13.3\% with 'School Action' code, $11.3 \%$ with 'School Action Plus' code where advice or support from external agencies is sought in consultation with parents, and $3.3 \%$ with a statement of SEN $[27,28]$. A commissioned national review concluded that many children, especially with 'School Action' code, were inaccurately 
identified as having SEN when their need was for better teaching and pastoral care [29]. The prevalence of SEN in our study was $11.2 \%$ overall (similarly to 'School Action Plus') and implies parents may have been better informed about SEN when it was genuine. The prevalence of SEN statement found in our study (4.9\%) was also comparable to that in England at the relevant time [27] and increases confidence in our findings.

Children with SEN have lower aspirations for their future education and employment [30] and substantially fewer of them progress to higher education, particularly those with a statement of SEN [28]. There is a need for broader screening and consideration of additional support for children born before full term, including among those born just a few weeks early. Our findings also suggest that the possible long-term implications of birth at early term gestations should be considered in decision making regarding planned births in pregnancies with no immediate detriment to mother or baby. Results are generalizable to settings with similar neonatal care and school support.

\section{Conclusion}

UK children born at earlier gestational ages are more likely to have SEN at age 11 compared with those born in week 40 , reaching a peak of $27.4 \%$ in children born very preterm. An increased risk of SEN exists even for children born at early term gestations and even when the birth was of spontaneous onset. SEN in children born preterm in not only more common, but also more complex. 


\section{Competing Interests}

No competing interests

\section{Acknowledgements}

We are grateful to the families of the Millennium Cohort Study and to the Medical Research Council (MRC) for funding this project (MR/M01228X/1). We would like to acknowledge the TIGAR Patient and Public Involvement (PPI) group and National Childbirth Trust (NCT) representatives for their input on the study objectives and the TIGAR Advisory Group for their input on the study design.

\section{Funding}

The TIGAR study was funded by a research grant from the Medical Research Council $(\mathrm{MR} / \mathrm{M} 01228 \mathrm{X} / 1)$

\section{Contributorship statement}

MAQ, NA, CC and SJ designed the study with input from EB, JJK, AM, SP and ORA. Statistical analysis was performed by NA, while MAQ, CC, SJ, EB, JJK, AM, SP, ORA and NA were all involved in the interpretation of the findings. NA wrote the initial draft of the manuscript and all authors contributed to draft of the manuscript and reviewed the final version.

\section{References}

1 Miller JE, Hammond GC, Strunk T, et al. Association of gestational age and growth measures at birth with infection-related admissions to hospital throughout childhood: a population-based, data-linkage study from Western Australia. Lancet Infect Dis 2016;16:952-61. doi:10.1016/S1473-3099(16)00150-X Woythaler M. Neurodevelopmental outcomes of the late preterm infant. Semin. Fetal Neonatal Med. 2019;24:54-9. doi:10.1016/j.siny.2018.10.002

3 Chan E, Quigley MA. School performance at age 7 years in late preterm and early term birth: a cohort study. Arch Dis Child Fetal Neonatal Ed 2014;99:F451-7. doi:10.1136/archdischild-2014-306124

4 Quigley MA, Poulsen G, Boyle E, et al. Early term and late preterm birth are associated with poorer school performance at age 5 years: a cohort study. Arch Dis Child - Fetal Neonatal Ed 2012;97:F167-73. doi:10.1136/archdischild-2011-300888

5 Twilhaar ES, de Kieviet JF, Aarnoudse-Moens CS, et al. Academic performance of children born preterm: a meta-analysis and meta-regression. Arch Dis Child Fetal Neonatal Ed 2018;103:F322-30. doi:10.1136/archdischild-2017-312916

6 Johnson S, Strauss V, Gilmore C, et al. Learning disabilities among extremely preterm children without neurosensory impairment: Comorbidity, neuropsychological profiles and scholastic outcomes. Early Hum Dev 2016;103:69-75. doi:10.1016/j.earlhumdev.2016.07.009

$7 \quad$ Hutchinson EA, De Luca CR, Doyle LW, et al. School-age outcomes of extremely preterm or extremely low birth weight children. Pediatrics 2013;131:e1053-61. doi:10.1542/peds.2012-2311 
Johnson S, Hennessy E, Smith R, et al. Academic attainment and special educational needs in extremely preterm children at 11 years of age: the EPICure study. Arch Dis Child Fetal Neonatal Ed 2009;94:F2839. doi:10.1136/adc.2008.152793

Odd D, Evans D, Emond A. Preterm Birth, Age at School Entry and Educational Performance. PLoS One 2013;8:e76615. doi:10.1371/journal.pone.0076615 Hospital Admission in Childhood. Pediatrics 2013;132:e1562-9. doi:10.1542/peds.2013-1737 MacKay DF, Smith GCS, Dobbie R, et al. Gestational age at delivery and special educational need: retrospective cohort study of 407,503 schoolchildren. PLoS Med 2010;7:e1000289. doi:10.1371/journal.pmed.1000289 NHS Digital. NHS Maternity Statistics 2018-19. 2019. Centre for Longitudinal Studies. 2007. Plewis I, Calderwood L, Hawkes D, et al. The Millennium Cohort Study: Technical Report on Sampling. Centre for Longitudinal Studies 2007. Poulsen G, Kurinczuk JJ, Wolke D, et al. Accurate reporting of expected delivery date by mothers 9 months after birth. J Clin Epidemiol 2011;64:1444-50. doi:10.1016/j.jclinepi.2011.03.007 American College of Obstetricians and Gyneocologists (ACOG), Society for maternal-fetal Medicine. Definition of term pregnancy committe opinion No. 579. 2013. Bonellie S, Chalmers J, Gray R, et al. Centile charts for birthweight for gestational age for Scottish singleton births. BMC Pregnancy Childbirth 2008;8:5. doi:10.1186/1471-2393-8-5 Zou G. A Modified Poisson Regression Approach to Prospective Studies with Binary Data. Am J Epidemiol 2004;159:702-6. doi:10.1093/aje/kwh090 Kelly $\mathrm{Y}$, lacovou $\mathrm{M}$, Quigley MA, et al. Light drinking versus abstinence in pregnancy - behavioural and cognitive outcomes in 7-year-old children: a longitudinal cohort study. BJOG 2013;120:1340-7. doi:10.1111/1471-0528.12246 Hansen K, Johnson J, Calderwood L, et al. Millennium Cohort Study: A Guide to the Datasets (First, Second, Third, Fourth and Fifth Surveys). London: : Centre for Longitudinal Studies 2014. Woodward LJ, Moor S, Hood KM, et al. Very preterm children show impairments across multiple neurodevelopmental domains by age 4 years. Arch Dis Child Fetal Neonatal Ed 2009;94. doi:10.1136/adc.2008.146282 Office for National Statistics. Births by gestational age at birth, England and Wales. 2018.https://www.ons.gov.uk/peoplepopulationandcommunity/birthsdeathsandmarriages/livebirths/ adhocs/10766birthsbygestationalageatbirthenglandandwales2018 (accessed 11 May 2020). Bentley JP, Roberts CL, Bowen JR, et al. Planned birth before 39 weeks and child development: A population-based study. Pediatrics 2016;138. doi:10.1542/peds.2016-2002 Fitzpatrick A, Carter J, Quigley MA. Association of Gestational Age With Verbal Ability and Spatial Working Memory at Age 11. Pediatrics 2016;138:e20160578. doi:10.1542/peds.2016-0578 MacKay DF, Smith GCS, Dobbie R, et al. Obstetric factors and different causes of special educational need: Retrospective cohort study of 407503 schoolchildren. BJOG An Int J Obstet Gynaecol 2013;120:297-307. doi:10.1111/1471-0528.12071 Franz AP, Bolat GU, Bolat $\mathrm{H}$, et al. Attention-deficit/hyperactivity disorder and very preterm/very low birth weight: A meta-analysis. Pediatrics. 2018;141. doi:10.1542/peds.2017-1645 Department of Education. Special Educational Needs in England. London: 2012. Table 6A; Table 6C. Department for Education. Special educational needs: an analysis and summary of data sources. 2019. doi:10.2319/051010-252.1 OFSTED. The special educational needs and disability review. 2010. Institute of Education. SEN, school life and future aspirations - Millennium Cohort Study. 2017. 


\section{Supplementary material}

Table S-1: Categorisation of reported reasons for SEN and number of observations per reason in the study sample

\begin{tabular}{|c|c|c|c|}
\hline Reason for SEN (categorised) & Specific reasons for SEN reported in MCS & $\begin{array}{l}\text { Predefined } \\
\text { answer / } \\
\text { open text } \\
\text { response* }\end{array}$ & $\begin{array}{l}\text { Number } \\
\text { of } \\
\text { events } \\
n * *\end{array}$ \\
\hline \multirow[t]{9}{*}{ Learning difficulties } & Dyslexia & Predefined & 406 \\
\hline & $\begin{array}{l}\text { Learning difficulties (including dyspraxia and } \\
\text { dyscalculia) }\end{array}$ & Predefined & 287 \\
\hline & Reading difficulties & Open text & 51 \\
\hline & Behind in studies & Open text & 25 \\
\hline & Handwriting/writing/spelling & Open text & 23 \\
\hline & Maths/numeracy difficulties & Open text & 17 \\
\hline & $\begin{array}{l}\text { Poor concentration skills (not specified } \\
\text { further) }\end{array}$ & Open text & 13 \\
\hline & Developmental delays (not specified further) & Open text & 9 \\
\hline & Poor short-term memory & Open text & 8 \\
\hline Autism Spectrum Disorder (ASD) & $\begin{array}{l}\text { Autism, Asperger's syndrome or autistic } \\
\text { spectrum disorder }\end{array}$ & Predefined & 235 \\
\hline \multirow{4}{*}{$\begin{array}{l}\text { Speech/language/communication } \\
\text { difficulties }\end{array}$} & Problem with speech or language & Predefined & 163 \\
\hline & English not first language & Open text & 11 \\
\hline & Poor communication skills & Open text & $\leq 5$ \\
\hline & Auditory processing disorder & Open text & $\leq 5$ \\
\hline $\begin{array}{l}\text { Attention-Deficit/Hyperactivity } \\
\text { Disorder (ADHD) }\end{array}$ & $\begin{array}{l}\text { Attention Deficit and Hyperactivity Disorder } \\
\text { (ADHD) }\end{array}$ & Predefined & 149 \\
\hline \multirow[t]{6}{*}{ Health or physical } & Medical or health problem & Predefined & 64 \\
\hline & Other physical disability & Predefined & 45 \\
\hline & Problem with hearing & Predefined & 43 \\
\hline & Problem with sight & Predefined & 35 \\
\hline & Poor motor skills (general) & Open text & 8 \\
\hline & Child has Down's Syndrome & Open text & 7 \\
\hline \multirow{5}{*}{$\begin{array}{l}\text { Behavioural } \\
\text { /emotional } \\
\text { /social difficulties }\end{array}$} & Behavioural problems/ hyperactivity & Predefined & 95 \\
\hline & Mental illness/ depression & Predefined & 9 \\
\hline & $\begin{array}{l}\text { Confidence/self motivation/self- } \\
\text { esteem/emotional problems/nervousness/ } \\
\text { anxiety }\end{array}$ & Open text & 12 \\
\hline & Bullying & Open text & $\leq 5$ \\
\hline & Family problems/trauma/home life & Open text & $\leq 5$ \\
\hline
\end{tabular}


Table S-2: Characteristics of the study sample compared with originally recruited cohort

\begin{tabular}{|c|c|c|}
\hline & $\begin{array}{l}\text { Original cohort } \\
\% *(n) \\
N=18,818\end{array}$ & $\begin{array}{l}\text { Study sample } \\
\%^{* *}(n) \\
N=12,031\end{array}$ \\
\hline \multicolumn{3}{|l|}{ Gestational age } \\
\hline$<32$ & $1.2(233)$ & $1.2(143)$ \\
\hline $32-33$ & $1.3(209)$ & $1.1(135)$ \\
\hline $34-36$ & $6.4(1,119)$ & $6.6(732)$ \\
\hline $37-38$ & $20.7(3,670)$ & $20.6(2,460)$ \\
\hline 39 & $21.5(3,876)$ & $21.3(2,613)$ \\
\hline 40 & $28.3(5,032)$ & $28.6(3,438)$ \\
\hline 41 & $20.7(3,672)$ & $20.6(2,560)$ \\
\hline Mean* maternal age (SD) & $28.8(5.9)$ & $28.2(6.0)$ \\
\hline White child ethnicity & $87.1(15,520)$ & $85.4(10,157)$ \\
\hline \multicolumn{3}{|l|}{ Partnership status } \\
\hline Married & $60.2(11,032)$ & $56.5(7,490)$ \\
\hline Cohabiting & $25.5(4,565)$ & $26.7(2,847)$ \\
\hline Single mother & $14.3(3,203)$ & $16.9(1,744)$ \\
\hline \multicolumn{3}{|l|}{ Maternal education } \\
\hline Higher (University) & $32.6(5,464)$ & $28.5(3,940)$ \\
\hline Medium (A-level) & $14.2(2,641)$ & $13.9(1,762)$ \\
\hline Lower (GCSE) & $38.0(7,017)$ & $39.8(4,432)$ \\
\hline None or other & $15.3(3,642)$ & $17.8(1,947)$ \\
\hline \multicolumn{3}{|l|}{ Household socioeconomic class } \\
\hline Managerial/professional & $44.7(7,267)$ & $40.5(5,232)$ \\
\hline Intermediate & $19.6(3,663)$ & $19.4(2,352)$ \\
\hline Routine/manual & $31.0(6,704)$ & $34.6(3,895)$ \\
\hline Never/long-term & $4.8(1,184)$ & $5.6(602)$ \\
\hline Male & $51.2(9,648)$ & $51.2(6,063)$ \\
\hline Mean birthweight in Kg (SD) & $3.3(0.6)$ & $3.3(0.6)$ \\
\hline Multiple birth & $2.9(522)$ & $3.0(331)$ \\
\hline Firstborn & $41.8(7,834)$ & $41.7(5,030)$ \\
\hline \multicolumn{3}{|l|}{ Maternal smoking } \\
\hline Never & $66.1(12,241)$ & $63.8(8,139)$ \\
\hline Gave up in pregnancy & $12.5(2,266)$ & $12.2(1,384)$ \\
\hline Smoked during pregnancy & $21.4(4,304)$ & $24.0(2,552)$ \\
\hline Alcohol during pregnancy & $7.5(1,344)$ & $7.5(865)$ \\
\hline Labour induced & $29.8(5,811)$ & $28.3(3,535)$ \\
\hline \multicolumn{3}{|l|}{ Mode of birth } \\
\hline Vaginal delivery & $77.7(14,526)$ & $78.9(9,370)$ \\
\hline Planned caesarean & $9.6(1,820)$ & $9.1(1,167)$ \\
\hline Emergency caesarean & $12.7(2,390)$ & $12.0(1,528)$ \\
\hline Neonatal intensive care & $9.5(1,785)$ & $9.6(1,149)$ \\
\hline \multicolumn{3}{|l|}{ Month of birth } \\
\hline September-December & $34.0(6,672)$ & $34.4(4,313)$ \\
\hline January-April & $32.0(5,990)$ & $31.4(3,833)$ \\
\hline May-August & $34.1(6,156)$ & $34.2(3,935)$ \\
\hline
\end{tabular}

* Percentages and means are weighted to account for sampling design and non-response to the MCS 
** Percentages and means are weighted to account for sampling design, non-response to the MCS and loss to follow-up at age 11

*** All percentages calculated from non-missing observations 
Table S-3: Sensitivity analysis of the association between gestational age and predefined reasons for multiple SENs at age 11 in the MCS children

\begin{tabular}{|c|c|c|c|c|c|c|c|c|}
\hline & Total & $\begin{array}{l}\text { Very preterm } \\
<32 \text { weeks }\end{array}$ & $\begin{array}{l}\text { Moderately } \\
\text { preterm } \\
\text { 32-33 weeks }\end{array}$ & $\begin{array}{l}\text { Late preterm } \\
\text { 34-36 weeks }\end{array}$ & $\begin{array}{l}\text { Early term } \\
\text { 37-38 weeks }\end{array}$ & $\begin{array}{l}\text { Full term } \\
39 \text { weeks }\end{array}$ & $\begin{array}{l}\text { Full term } \\
40 \text { weeks }\end{array}$ & $\begin{array}{l}\text { Late term } \\
41 \text { weeks }\end{array}$ \\
\hline $\mathbf{N}$ & 11,929 & 140 & 134 & 720 & 2,432 & 2,580 & 3,392 & 2,531 \\
\hline $\begin{array}{l}\text { Multiple SENs } \\
\text { n (\%)* }\end{array}$ & $260(2.6)$ & $10(8.2)$ & $3(2.5)$ & $26(5.9)$ & $61(2.9)$ & $61(2.6)$ & $65(2.0)$ & $34(1.6)$ \\
\hline RR (95\% CI) & & $4.08(2.08,8.03)$ & $1.26(0.36,4.36)$ & $2.94(1.57,5.50)$ & $1.42(0.95,2.14)$ & $1.31(0.86,1.99)$ & 1.00 & $0.82(0.51,1.31)$ \\
\hline $\begin{array}{l}\text { Adjusted** } \\
\text { RR }(95 \% \mathrm{Cl})\end{array}$ & & $3.37(1.60,7.11)$ & $1.15(0.32,4.18)$ & $2.62(1.42,4.82)$ & $1.36(0.91,2.04)$ & $1.27(0.84,1.92)$ & 1.00 & $0.85(0.53,1.36)$ \\
\hline
\end{tabular}

* Weighted percentages

** Adjusted for white ethnicity, maternal education, household socioeconomic class, child sex, month of birth, multiple birth 